\section{Hipotireoidismo congênito primário em cão: relato de caso}

\author{
Congenital hypothyroidism in dog: case report
}

\begin{abstract}
Rafaela Bruno Faria Pisani', Priscila Cardim de Oliveira² ${ }^{2}$ Isabela Pessôa Barbieri Bastos ${ }^{3} \&$ Julio Israel Fernandes ${ }^{4 *}$ 'Médica veterinária, MSc. Programa de Pós-graduação em Medicina Veterinária - PPGMV, Instituto de Veterinária IV, Universidade Federal Rural do Rio de Janeiro - UFRRJ, Seropédica, RJ, Brasil

${ }^{2}$ Médica veterinária, MSc. Programa de Pós-graduação em Ciências Veterinárias - PPGCV, Instituto de Veterinária IV, Universidade Federal Rural do Rio de Janeiro - UFRRJ, Seropédica, RJ, Brasil

Médica veterinária. Programa de Residência Médica em Área Profissional de Saúde em Medicina Veterinária, Instituto de Veterinária - IV, Universidade Federal Rural do Rio de Janeiro - UFRRJ, Seropédica, RJ, Brasil

${ }^{4}$ Médico veterinário, Dsc. Departamento de Medicina e Cirurgia Veterinária, Instituto de Veterinária - IV, Universidade Federal Rural do Rio de Janeiro - UFRRJ, Seropédica, RJ, Brasil
\end{abstract}

\section{Resumo}

O hipotireoidismo congênito canino é um distúrbio endócrino raro e subdiagnosticado. Sua verdadeira incidência é desconhecida, pois muitos cães com esta anomalia morrem antes de completarem três meses de idade. Por atuar em diversos órgãos, a falta dos hormônios da tireóide causam diversos sinais clínicos relacionados ao baixo metabolismo, dentre eles: deficiência mental e anomalias no desenvolvimento do esqueleto. O diagnóstico é feito através do histórico, exames laboratoriais de triagem somado aos achados clínico-epidemiológico e dosagens séricas dos hormônios tireoidianos, tiroxina total (T4T), tiroxina livre (T4L) e hormônio estimulante da tireóide (TSH). O presente trabalho relata um caso de hipotireoidismo congênito canino na raça Chow-Chow de um ano de idade diagnosticado no Hospital Veterinário da Universidade Federal Rural do Rio de Janeiro. O animal foi submetido ao tratamento de reposição hormonal com levotiroxina sódica o que resultou em melhora do quadro clinico.

Palavras-chave: tiroxina, tireóide, nanismo desproporcional.

\begin{abstract}
Canine congenital hypothyroidism is a rare and underdiagnosed endocrine disorder, their true incidence is unknown because many dogs with this condition die before reaching three months of age. The disorder can cause a range of clinical signs as the lack of thyroid hormones on the animal's body because of low metabolism signs of multiple organs. Affected dogs may have mental retardation and abnormalities in skeletal development. Diagnosis is made through the animal's history, laboratory screening tests added to the clinical and epidemiological findings and serum levels of thyroid hormones. This paper reports a case of canine congenital hypothyroidism in a Chow-Chow dog, with one year old, diagnosed at the Veterinary Hospital of the Federal Rural University of Rio de Janeiro. The animal was submitted to hormone replacement therapy with levothyroxine Sodium resulting in clinical improvement.
\end{abstract}

Keywords: thyroxine, thyroid, disproportionate dwarfism.

\section{Introdução}

O hipotireoidismo congênito é uma desordem endócrina relativamente comum em bebês humanos, diferentemente do que ocorre em cães. Apenas 3,6\% dos casos de hipotireoidismo canino ocorrem em cães com menos de um ano de idade (Greco, 2006). É possível que a real prevalência seja maior do que a relatada, visto que muitos filhotes de cães acometidos morrem no início da vida e são considerados erroneamente como filhotes portadores de síndrome do "definhamento do filhote" (Mooney \& Shiel, 2015). O hipotireoidismo congênito pode ser primário ou central. Quando primário (acomete a glândula tireóide) pode ser causado por aplasia ou hipoplasia da glândula tireóide, ectopia tireoidiana, disormoniogênese, tratamento materno com iodo radioativo, deficiência de iodo (bócio endêmico), tireoidite autoimune (Greco et al., 1985). Quando tem origem central pode ser causado por deficiência de TRH (tireotropina) ou TSH (hormônio estimulante da tireóide) ou ainda resistência aos receptores a esses hormônios (LaFranchi et al., 2007).

\section{BJ $\mathrm{M}$ \\ Brazilian Journal of Veterinary Medicine}

p-ISSN 0100-2430

Como citar: Pisani, R. B. F., Oliveira, P. C., Bastos, I. P. B., \& Fernandes, J. I. (2017). Hipotireoidismo congênito primário em cão: relato de caso. Brazilian Journal of Veterinary Medicine, 39(4). 279-283. doi: 10.29374/2527-2179.bjvm020817

Fonte de financiamento: Os exames foram realizados com recursos financeiros do tutor e os custos de publicação serão financiados pelos autores.

Conflito de interesses: Os autores declaram não haver conflito de interesses que precisam ser informados.

Recebido: Maio 20, 2017.

Aceito: Novembro 03, 2017.

O estudo do caso foi realizado no Hospital Veterinário da Universidade Federal Rural do Rio de Janeio - UFRRJ, Seropédica, RJ, Brasil.

\author{
*Correspondência \\ Julio Israel Fernandes \\ Programa de Pós-graduação em Medicina \\ Veterinária, Universidade Federal Rural do Rio \\ de Janeiro - UFRRJ \\ Rodovia BR 465, Km 7 \\ CEP 23897-000, Seropédica, RJ, Brasil \\ E-mail:vetjulio@yahoo.com.br
}

Copyright Pisani et al. Este é um artigo publicado em acesso aberto (Open Access) sob a licença Creative Commons Attribution Non-Commercial, que permite uso, distribuição e reprodução em qualquer meio, sem restrições desde que sem fins comerciais e que o trabalho original seja corretamente citado. 
Foram relatados casos de disormoniogenese em cães filhotes das raças Fox Terrier (Fyfe et al., 2003) e Rat Terrier (Pettigrew et al., 2007) herdada como característica autossômica recessiva. Casos de disgenesia da tireóide em cães mestiços de Pastor alemão foram relatados por Greco et al. (1985) e em Boxer relatado por Mooney \& Anderson (1993). O hipotireoidismo congênito central foi relatado em Shnauzer gigante (Greco et al., 1991) e em um cão da raça Boxer (Mooney \& Anderson, 1993).

Os hormônios da tireóide são essenciais para o desenvolvimento após o nascimento, principalmente para o sistema nervoso e esquelético dos filhotes. A falta ou diminuição desses hormônios nesta fase leva a anomalias do sistema nervoso central e periférico além de atraso mental. Em geral, os cães nascem com peso normal e as vezes são os maiores da ninhada (Scott-Moncrieff \& Guptill-Yoran, 2005). No entanto, entre 3 a 8 semanas de idade ocorrem os primeiros sinais de falha no crescimento principalmente quando se compara o tamanho do animal acometido com os dos irmãos.

Os sinais de nanismo desproporcional se desenvolvem ao longo dos meses seguintes sendo caracterizado por cabeças largas, encurtamento de orelhas, pescoços curtos e grossos e membros curtos (Feldman \& Nelson, 2004). Presença de macroglossia, hipotermia, erupção dentária atrasada, ataxia e distensão abdominal também já forma relatados (Chastain et al., 1983; Mooney \& Anderson, 1993; Fyfe et al., 2003). Estado mental prejudicado se manifesta como embotamento mental e letargia, sonolência ou falta de ludicidade em comparação com os irmãos saudáveis da ninhada (Feldman \& Nelson 2004). A pelagem pode manter características de filhote ou, ainda, haver alopecia localizada na cauda denominada "cauda de rato" (Scott et al. 2001; Feldman \& Nelson, 2004). Sinais dermatológicos incluem retenção do pelame juvenil, pele seca e espessa, e afinamento do pelo, que evolui para alopecia. Com o tempo, problemas dermatológicos crônicos, como episódios recorrentes de otite externa, excesso de dobra cutânea sobre o corpo e rosto, seborreia (Mooney \& Anderson, 1993) e alopecia com hiperpigmentação (Medleau et al., 1985) podem se desenvolver, como visto no hipotireoidismo em adultos.

Características laboratoriais incluem hipercolesterolemia e/ou hipertrigliceridemia em jejum e anemia. Hipercolesterolemia se desenvolve no hipotireoidismo congênito por conta da diminuição do metabolismo hepático e diminuição na excreção fecal de colesterol nesses animais (Scott Moncrieff, 2015). A diminuição do estímulo tireoidiano sobre a medula e consequentemente dos precursores eritropoiéticos, resulta em uma anemia normocítica normocrômica leve em alguns filhotes com hipotireoidismo (Cline \& Berlin, 1963). Anemia normocítica, normocrômica não regenerativa foi identificada em aproximadamente 30\% dos cães (David, 2001).

O diagnóstico de hipotireoidismo congênito é baseado nos sinais clínicos, associados aos achados laboratoriais e teste de função da tireóide. Os hormônios da tireóide comumente medidos são os mesmos para diagnóstico de hipotireoidismo adquirido e incluem dosagem séricas de T4L (T4 livre), T4T (T4 total) e TSH (Hormônio estimulador da tireóide). A concentração de T4 total é utilizada como teste de rastreio para o hipotireoidismo e apresenta alta sensibilidade, mas baixa especificidade, uma vez que níveis subnormais de T4T podem indicar doença não tireoidiana (Feldman \& Nelson 2004). Já a medição de T4L é menos influenciada por outros fatores e apresenta grau de especificidade $>90 \%$, uma vez que mede a porção metabolicamente ativa do T4 a qual representa a quantidade de hormônio disponível para absorção tecidual (Dixon et al., 1999). Em filhotes de cães com hipotireoidismo primário (digenesia da tireóide, disormoniogênese) seriam esperadas concentrações elevadas de TSH endógenos (Greco D.S., 2011; Scott-Moncrieff, 2015).

Várias estratégias terapêuticas têm sido recomendadas para o tratamento de hipotireoidismo com doses variando entre 10mcg/kg até $44 \mathrm{mcg} / \mathrm{kg}$ a cada 12 ou 24 horas (Dixon et al., 2002). A monitorização terapêutica é essencialmente a mesma que a realizada no hipotireoidismo adquirido com medição de T4 total pós Levotiroxina para adequar as doses medicamentosas. A resposta à terapia pode ser excelente e rápida, e muitas anormalidades clínicas e laboratoriais se resolvem gradualmente, entre um e três meses de tratamento, enquanto que as mudanças de pele e anormalidades esqueléticas pode levar mais tempo, excedendo seis meses. O prognóstico a longo prazo é reservado no hipotireoidismo congênito e a resposta ao tratamento depende da etiologia e duração do tratamento. As complicações mais importantes são alterações músculo-esqueléticas e deficiência mental, embora a maioria dos outros sinais clínicos tendam a se resolver. A deficiência mental pode ser irreversível se a terapia for iniciada depois de seis meses de idade (Greco \& Chastain, 2001). Por ser um distúrbio raro, o objetivo do trabalho é relatar um animal diagnosticado com a doença e que respondeu de forma satisfatória ao tratamento instituído. 


\section{Histórico}

Uma cadela da raça Chow-Chow, com um ano de idade, foi atendida no Hospital Veterinário da Universidade Federal Rural do Rio de Janeiro (HV/UFRRJ). O proprietário relatou que ela foi encontrada na rua apresentando pequenas lesões na pele, apatia e anemia. No exame clínico foi observado cabeça larga, com lateralização desta para o lado direito provavelmente decorrente de otite, tamanho corporal pequeno comparado ao padrão da raça, hipotricose generalizada, presença de lanugem hiperpigmentação em dorso, alopecia localizada em cauda "cauda de rato" (Figura 1B) e livre de ectoparasitas (Figura 1). Foram observadas alterações oftálmicas compatíveis com entrópio, triquíase e conjuntivite (Figura 1). No exame da cavidade oral apresentava persistência da dentição primária, macroglossia, periodontite leve e mucosas normocoradas. Na ausculta cardio - respiratória foi constatado bradicardia, bradipnéia e estertor pulmonar. Durante o exame mostrou-se apática, sonolenta e por vezes, dormindo. Demais padrões clínicos estavam dentro da normalidade. Foi realizado ainda raspado de pele com resultado negativo para a presença de ácaros.

Foram solicitados hemograma com pesquisa de hemoparasitas, além de bioquímica (ALT, AST, FA, Uréia, Creatinina, Colesterol e Triglicerídeos) e testes hormonais por radioimunoensaio (cortisol através do teste de supressão com dexametasona, T4 livre, T4 total e TSH). Os exames mostraram anemia normocítica normocrômica leve, leucometria global normal, porém com presença de linfopenia, além de trombocitopenia e ausência de hemoparasitas na amostra. Enzimas hepáticas e renais estavam dentro dos parâmetros de normalidade. As dosagens de colesterol e triglicerídeos em jejum foram respectivamente 441mg/dL (referência: 153mg/dL-278mg/dL) e $111 \mathrm{mg} / \mathrm{dL}$ (referência: 40mg/dL-169mg/dL). O teste de supressão por baixa dose de dexametasona para verificação do cortisol após 8 horas foi de $1 \mathrm{ng} / \mathrm{ml}$, valor dentro dos limites de referência (normal < 10ng/ml). Nas dosagens de T4 livre, T4 total e TSH, observou-se valores respectivamente 0,3ng/ml (0,8ng/ml-3,0ng/ml); 5,0ng/ml (7,3ng/ml-29ng/ml); 0,62ng/ml (0,04ng/ml-0,4ng/ml).

Após análise dos resultados dos exames verificou-se que estes eram compatíveis com hipotireoidismo primário congênito, sendo instituído o tratamento através da reposição hormonal com Levotiroxina Sódica na dose de $15 \mathrm{mcg} / \mathrm{kg}$ a cada 12 horas durante quatro semanas com

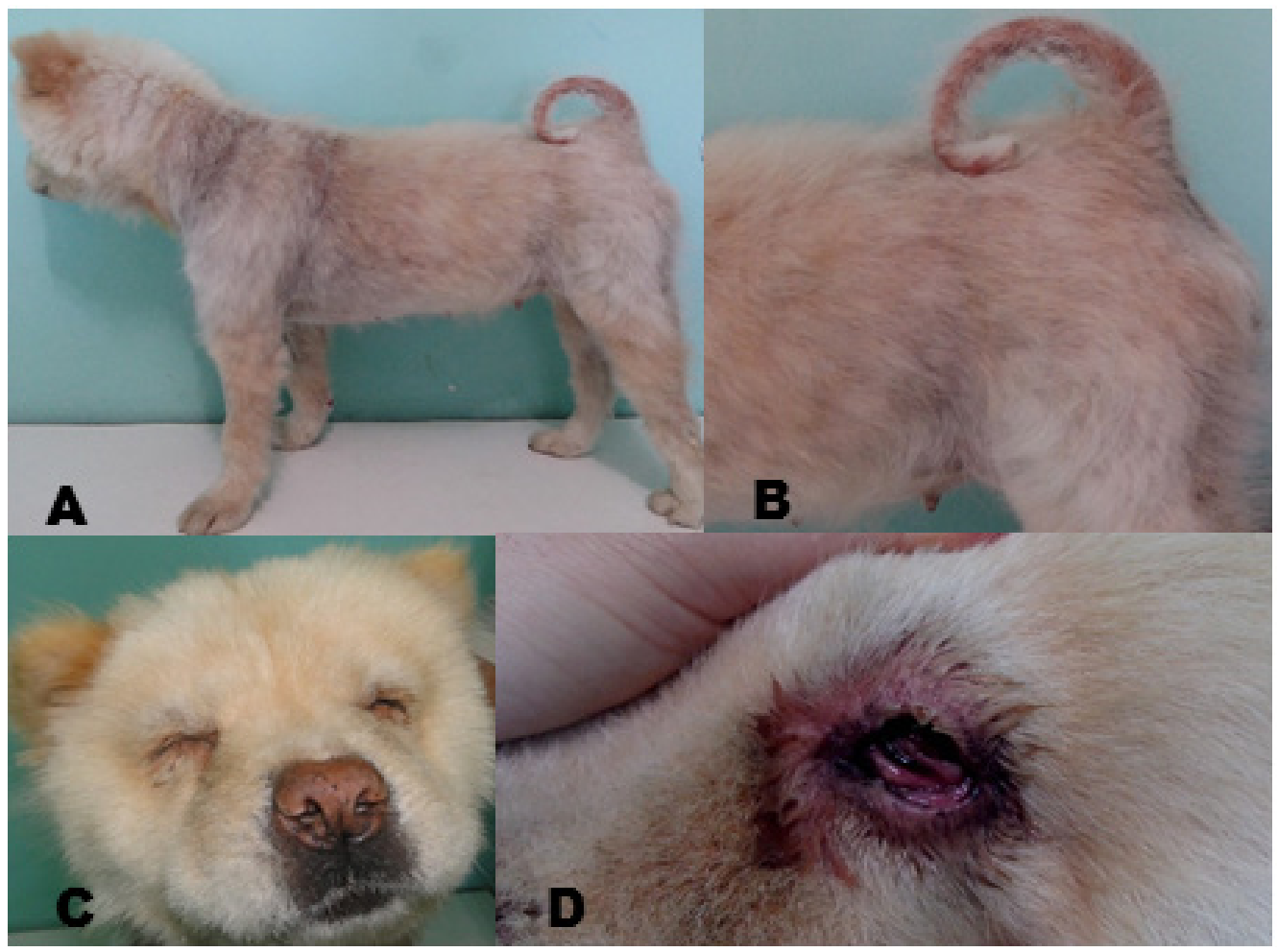

Figura 1. Animal antes do tratamento: (A) Estatura do corpo menor comparada ao padrão da raça, lateralização da cabeça para o lado direito, hipotricose localizada principalmente em pescoço e dorso; (B) "Cauda de rato"alopecia localizada em cauda; (C) Cabeça larga, plano nasal largo; (D) Distúrbios oftálmicos (triquíase, secreção ocular, abertura incompleta dos olhos). 


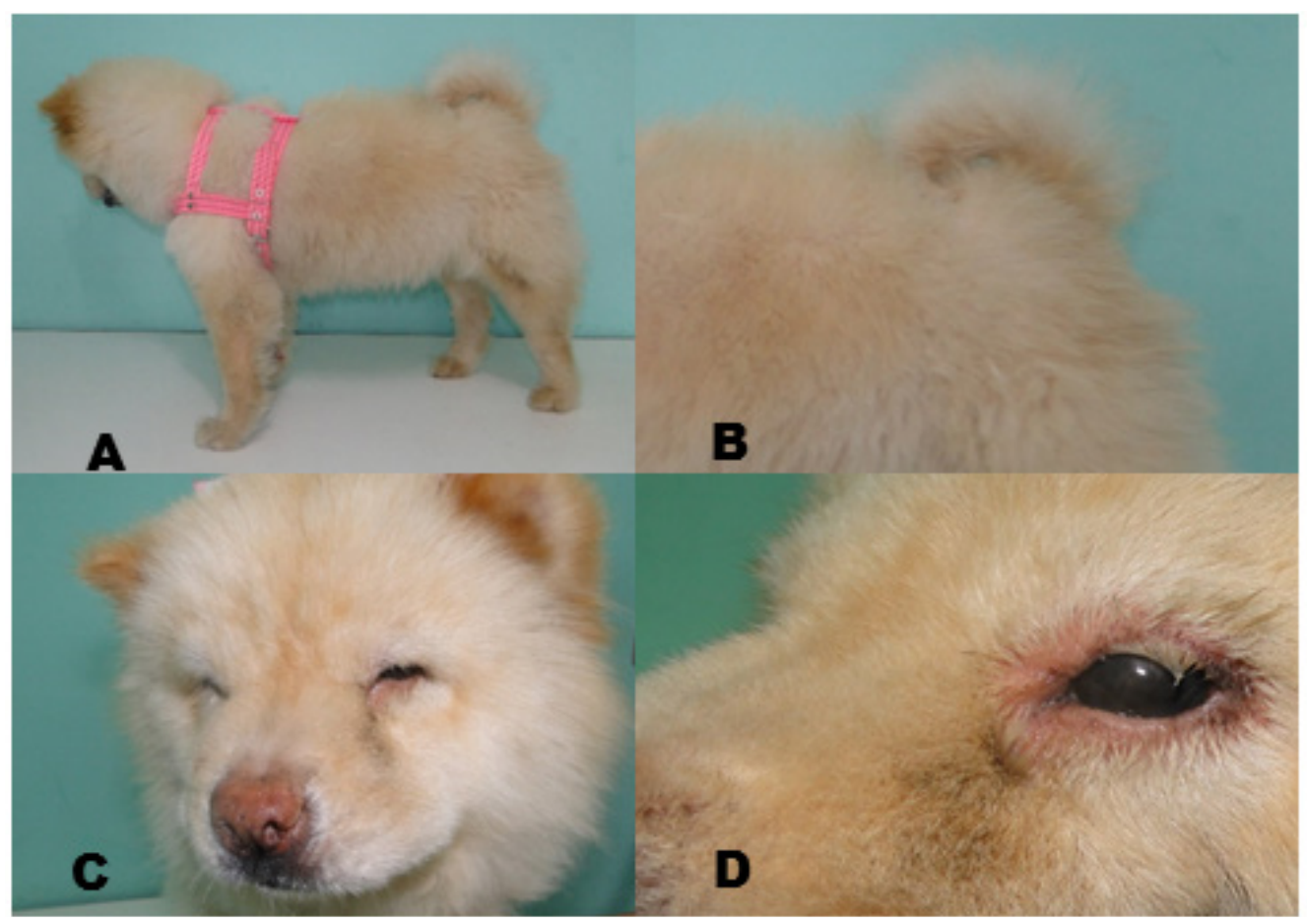

Figura 2. Animal após 60 dias de tratamento com levotiroxina: (A) Melhora da hipotricose no dorso e pescoço; (B) Crescimento do pêlo na cauda; (C) e (D) ausência de secreção ocular

aumento gradual para $22 \mathrm{mcg} / \mathrm{kg}$ a cada 12 horas. Para tratamento oftálmico utilizou-se colírio lubrificante a antibiótico tópico até estabilização para cirurgia de correção.

Após 60 dias de tratamento animal retornou para reavaliação onde notou-se grande melhora na qualidade da pelagem, crescimento de pelos mais fortes, sem presença de áreas de hipotricose e melhora da secreção ocular (Figura 2) além de um comportamento mais ativo diferente do que foi observado na primeira consulta.

\section{Discussão}

O hipotireoidismo congênito é de rara ocorrência e acomete mais comumente filhotes de até um ano de idade, sendo relatado em algumas raças de cães (Fyfe et al., 2003; Pettigrew et al., 2007; Greco et al., 1991; Mooney \& Anderson, 1993).

De acordo com Feldman \& Nelson (2004), o sinal de nanismo desproporcional caracterizou-se no presente relato por cabeça larga, apatia e sonolência. As alterações de macroglocia e persistência da dentição primária presentes no Chow-Chow atendido, também foram relatadas por Chastain et al. (1983), Mooney \& Anderson (1993) e Fyfe et al. (2003). Já as alterações dermatológicas como alopecia, hiperpigmentação da pele, presença de lanugem observados no canino atendido corroboram com as lesões dermatológicas descritas por Mooney \& Anderson (1993), Medleau et al. (1985). A presença de alopecia localizada em cauda "cauda de rato" outro achado compatível com hipotoreoidismo, igualmente observado no animal, também foi descrito por outros autores (Scott et al., 2001; Feldman \& Nelson, 2004).

As alterações laboratoriais compatíveis com hipotireoidismo como hipercolesterolemia estão de acordo com Scott Moncrieff (2015), além da anemia normocítica normocrômica reportada por Cline \& Berlin (1963) e David (2001). De acordo com Feldman \& Nelson (2004) o T4T poderia sofrer influência de doenças não tireoidianas e se apresentar abaixo dos níveis de normalidade caracterizando falso positivo para hipotiroidismo. Para evitar este fato foi realizado dosagem de cortisol após supressão com dexametasona e este apresentou valores normais. Também foi dosado T4 L que de acordo com Dixon et al. (1999) apresenta especificidade >90\% para o diagnóstico de hipotireoidismo e este também se apresentou abaixo dos níveis de normalidade. O TSH ao se 
apresentar aumentado corroborou com o diagnóstico de Hipotireoidismo congênito primário de acordo com Greco (2011) e Scott-Moncrieff (2015).

O tratamento de escolha foi a Levotiroxina sódica na dose inicial de $15 \mathrm{mcg} / \mathrm{kg}$ a cada 12 horas em jejum durante quatro semanas, realizando o aumento da dose para $22 \mathrm{mcg} / \mathrm{kg}$ a cada 12 horas, conforme sugerido por Dixon et al. (2002). Com 60 dias de tratamento o animal já apresentou melhora dermatológica o que segundo Dixon et al. (2002) poderia levar até seis meses, além de um comportamento mais ativo, contrariando o que foi proposto por Greco \& Chastain (2001) onde sinais mentais poderiam ser irreversíveis.

\section{Conclusão}

Cães filhotes a jovens, com sinais clínicos de nanismo desproporcional, persistência de dentição primária, macroglossia, apatia, sonolência, presença de lanugem, hipotricose e hiperpigmentação devem ser submetidos à exames laboratoriais e dosagem de hormônios tireoidianos a fim de realizar um diagnóstico preciso e tratamento precoce, visando o aumento de sua sobrevida.

O tratamento instituído com levotiroxina, mesmo em um animal com mais de seis meses, permitiu a melhora clínica do animal.

\section{Referências}

Chastain, C. B., McNeel, S. V., Graham, C. L., \& Pezzanite, S. C. (1983). Congenital hypothyroidism in a dog due to an iodide organification defect. American Journal of Veterinary Research, 44(7), 1257-1265. PMid:6881664.

Cline, M. J., \& Berlin, N. I. (1963). Erythropoiesis and red cell survival in the hypothyroid dog. The American Journal of Physiology, 204(3), 415-418. http://dx.doi.org/10.1152/ajplegacy.1963.204.3.415. PMid:14021760.

David, L. P. (2001). Conditions associated with canine hypothyroidism. The Veterinary Clinics of North America, 31(5), 935-950. http://dx.doi.org/10.1016/S0195-5616(01)50006-6. PMid:11570133.

Dixon, R. M., Reid, S. W. J., \& Mooney, C. T. (1999). Epidemiological, clinical, hematological and biochemical characteristics of canine hypothyroidism. Veterinary Record, 145, 481-487.

Dixon, R. M., Reid, S. W. J., \& Mooney, C. T. (2002). Treatment and therapeutic monitoring of canine hypothyroidism. The Journal of Small Animal Practice, 43(8), 334-340. http://dx.doi.org/10.1111/i.1748-5827.2002.tb00082.x. PMid:12201441.

Feldman, E. C., \& Nelson, R. W. (2004). Hypothyroidism. In E. C. Feldman \& R. W. Nelson. Canine and feline endocrinology and reproduction (3rd ed., pp. 86-151). St. Louis: Elsevier-Saunders.

Fyfe, J. C., Kampschmidt, K., Dang, V., Poteet, B. A., He, Q., Lowrie, C., Graham, P. A., \& Fetro, V. M. (2003). Congenital hypothyroidism with goiter in toy fox terriers. Journal of Veterinary Internal Medicine, 17(1), 50-57. http:// dx.doi.org/10.1111/j.1939-1676.2003.tb01323.x. PMid:12564727.

Greco, D. S. (2006). Pedriatric endocrinology. Veterinary Clinical Small Animal, 36(3), 549-556.

Greco, D. S. (2011). The endocrine system. In Peterson M. E. \& Kutzler M. A. (Eds.), Small animal pediatrics (pp. 492-495). Missouri: Elsevier Saunders. http://dx.doi.org/10.1016/B978-1-4160-4889-3.00045-0.

Greco, D. S., \& Chastain, C. B. (2001). Endocrine and metabolic systems. In J. D. Hoskins (Ed.), Veterinary pediatrics (3rd ed., pp 344-370). Philadelphia: WB Saunders. http://dx.doi.org/10.1016/B978-0-7216-7665-4.50020-6.

Greco, D. S., Feldman, E. C., Peterson, M. E., Turner, J. L., Hodges, C. M., \& Shipman, L. W. (1991). Congenital hypothyroid dwarfism in a family of Giant Schnauzers. Journal of Veterinary Internal Medicine, 5(2), 57-65. http://dx.doi.org/10.1111/j.1939-1676.1991.tb00932.x. PMid:2061865.

Greco, D. S., Peterson, M. E., Cho, D. Y., \& Markovits, J. E. (1985). Juvenile-onset hypothyroidism in a dog. Journal of the American Veterinary Medical Association, 187(9), 948-950. PMid:4055523.

LaFranchi, S., Kliegman, R. M., Jenson, H. B., Stanton, B. F., \& Behrman, R. E. (2007). Disorders of the thyroid gland. In Nelson Textbook of Pediatrics (17th ed., pp. 2316-2325). Philadelphia: WB Saunders.

Medleau, L., Eigenmann, J. E., Saunders, H. M., \& Goldschmidt, M. H. (1985). Congenital hypothyroidism in a dog. Journal of the American Animal Hospital Association, 21, 341-344.

Mooney, C. T., \& Anderson, T. J. (1993). Congenital hypothyroidism in a boxer dog. The Journal of Small Animal Practice, 34(1), 31-35. http://dx.doi.org/10.1111/j.1748-5827.1993.tb02573.x.

Mooney, C. T., \& Shiel, R. E. (2015). Hipotireoidismo em cães, In C. T. Mooney \& M. E. Peterson (Eds.), Manual de endocrinologia em cães e gatos (4a ed., pp. 81-82). São Paulo: Rocca.

Pettigrew, R., Fyee, J. C., Gregory, B. L., Lipsitz, D., DeLahunta, A., Summers, B. A., \& Shelton, G. D. (2007). Hypomyelination in rat terrier dogs with congenital goiter and a mutation in the thyroid peroxidase gene. Veterinary Pathology, 44(1), 50-56. http://dx.doi.org/10.1354/vp.44-1-50. PMid:17197623.

Scott, D. W., Miller Junior, W. H., \& Griffin, C. E. (2001). Muller \& Kirk's Small Animal Dermatology (6th ed., pp. 1528). Philadelphia: Saunders

Scott-Moncrieff, J. C. (2015). Hypothyroidism. In E. C. Feldman, R. W. Nelson, C. Reusch \& J. C. Scott-Moncrieff. Canine and feline endocrinology (4th ed., pp. 77-395). St. Louis: Elsevier-Saunders.

Scott-Moncrieff, J. C. R., \& Guptill-Yoran, L. (2005). Hypothyroidism. In S. J. Ettinger \& E. C. Feldman (Eds.), Textbook of Veterinary Internal Medicine (6th ed., pp. 1535-1543). St Louis: Elsevier-Saunders. 